\title{
Monodisperse Binary Nano-composite in Silica with Enhanced Magnetization for Magnetic Separation
}

\author{
Chih Hao Yu, Chester C. H. Lo, Kin Tam, and Shik Chi Tsang *
}

Supporting Information (SI):

S Figure 1 shows a typical X-ray diffraction (XRD) of iron-platinum/iron oxide in silica. The XRD pattern shows extremely broad peaks of $38-43^{\circ}(2 \theta)$ and $45-50^{\circ}(2 \theta)$ marked in black arrows, corresponding to fcc $\mathrm{FePt}<111>$ and $<200>$ in the as-synthesized $\mathrm{FePt}-\mathrm{Fe}_{3} \mathrm{O}_{4}$ nanoparticles from the polyol process. Assuming the FePt core is spherical in shape, the average particle diameter is calculated from the full width at half maximum (FWHM) of a chosen peak to be $3.0 \mathrm{~nm}$ according to the Scherrer equation. This core size also matches the observed size from the TEM (not shown). Three strong peaks characteristic of iron oxide at around $30^{\circ}(2.95), 35.5^{\circ}(2.51)$, and $62.5^{\circ}(1.48)$ (marked in blue) are clearly identified. It is noted that the patterns match well with either crystalline magnetite $\left(\mathrm{Fe}_{3} \mathrm{O}_{4}\right)$ or maghemite $\left(\gamma-\mathrm{Fe}_{2} \mathrm{O}_{3}\right)$ phases. However, assignment to one of these phases or to the mixture of them based entirely on XRD proves very difficult because of their closely related structures (with almost identical patterns) and peak broadening due to the nano-metric particle size. Regarding to the preparative procedure in the inert gas, it is believed that the iron oxide is likely to be in $\mathrm{Fe}_{3} \mathrm{O}_{4}$ phase. Upon the heat treatment $\left(500^{\circ} \mathrm{C}, 2 \mathrm{~h}\right)$ of the $\mathrm{FePt}-\mathrm{Fe}_{3} \mathrm{O}_{4}$, the average size of $\mathrm{FePt}_{-}-\mathrm{Fe}_{3} \mathrm{O}_{4}$ is found to be $4.5 \mathrm{~nm}$, which is similar to those of the as-synthesized sample. It is evident that the FePt peaks are slightly shifted to the right, suggesting that the fcc FePt has been converted to the fct FePt (the extra peaks are identified to be the fct superlattice peaks). 


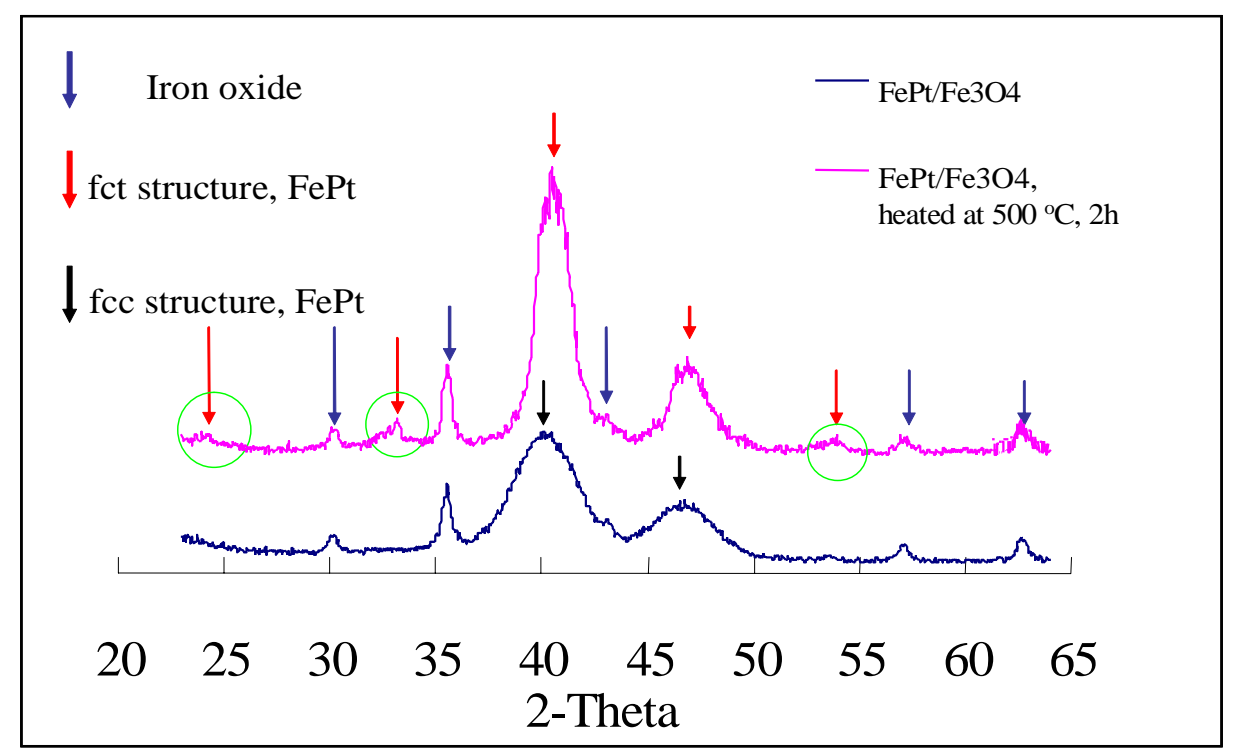

S Figure 1: X-ray powder diffraction spectra of $\mathrm{FePt} / \mathrm{Fe}_{3} \mathrm{O}_{4}$ before and after heat treatment.
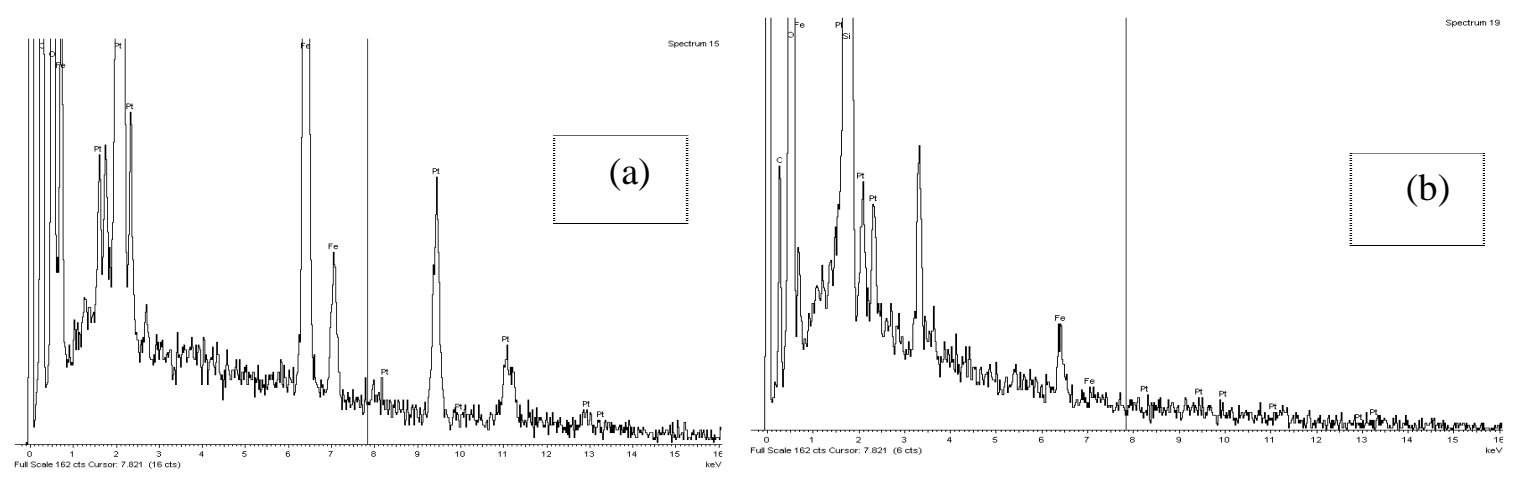

S Figure 2: EDX spectra of (a) $\mathrm{FePt}-\mathrm{Fe}_{3} \mathrm{O}_{4}$ nanocomposite; (b) $\mathrm{FePt}-\mathrm{Fe}_{3} \mathrm{O}_{4}$ nanocomposite in silica.

S Figures $2 \mathrm{a}$ and $2 \mathrm{~b}$ display the elemental mapping of the isolated particles of the $\mathrm{FePt}-\mathrm{Fe}_{3} \mathrm{O}_{4}$ with and without silica coating before the heat treatment. After taking the correction of the response factor for each element into account, the atomic ratios of the particle before the application of the silica coating are $\mathrm{Fe}$ : $\mathrm{Pt}=$ 6.33: 2.03 and with the silica coating are $\mathrm{Fe}: \mathrm{Pt}: \mathrm{Si}=0.34: 0.11: 22.0$ with a standard deviation of $\pm 0.2 \%$. (carbon and oxygen are excluded in the analysis because the use of carbon filmed holder which also affects the analysis of the oxygen content). The result clearly demonstrate that the exchange coupled nano-magnet is successful placed in a silicon rich matrix. 


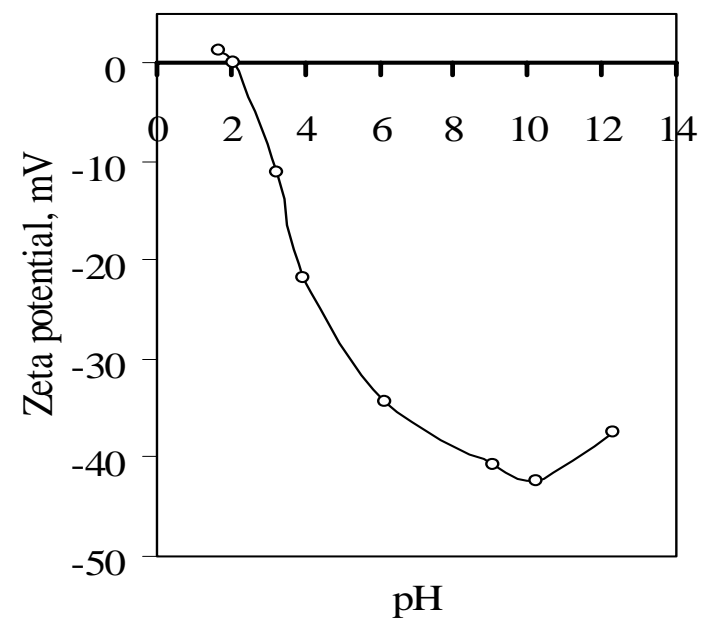

S Figure 3: Zeta potential measurement showing that the surface isoelectric potential (IEP) of $\mathrm{FePt}-\mathrm{Fe}_{3} \mathrm{O}_{4}$ particles is modified to 2.05 which corresponds well to the silica IEP value in literature value.

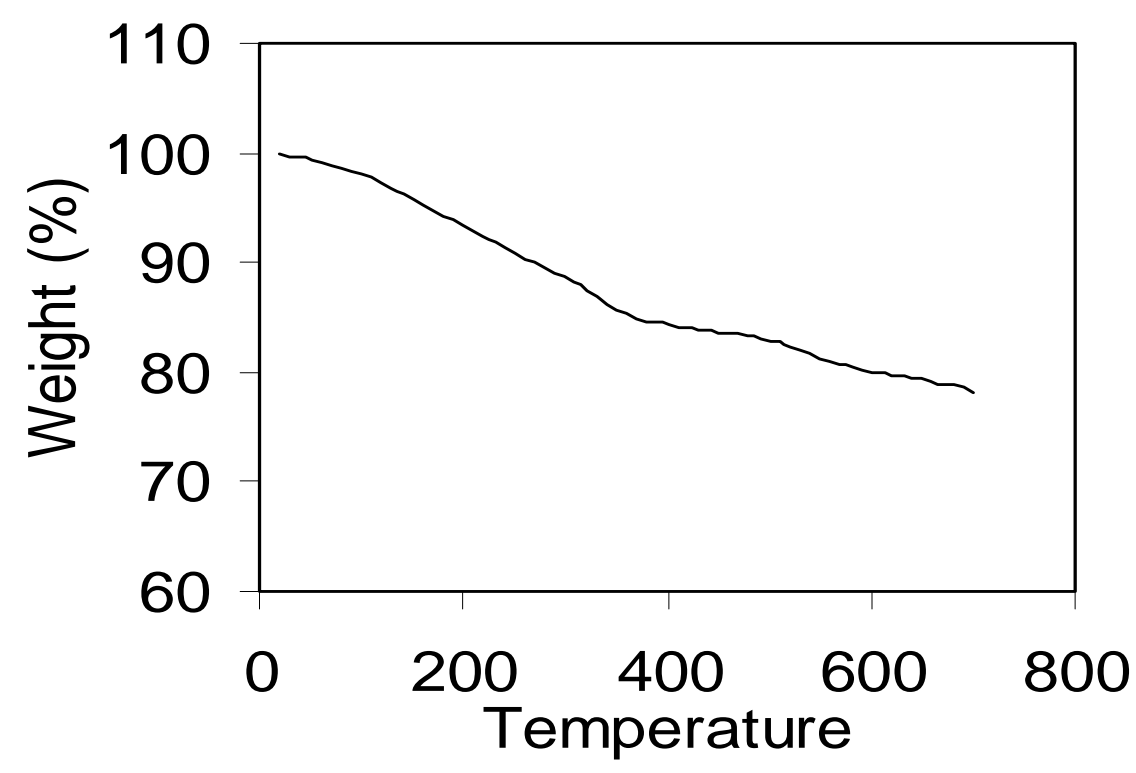

S Figure 4: TGA analysis of $\mathrm{FePt}-\mathrm{Fe}_{3} \mathrm{O}_{4}$ showing the reduction of sample above $300^{\circ} \mathrm{C}$ 


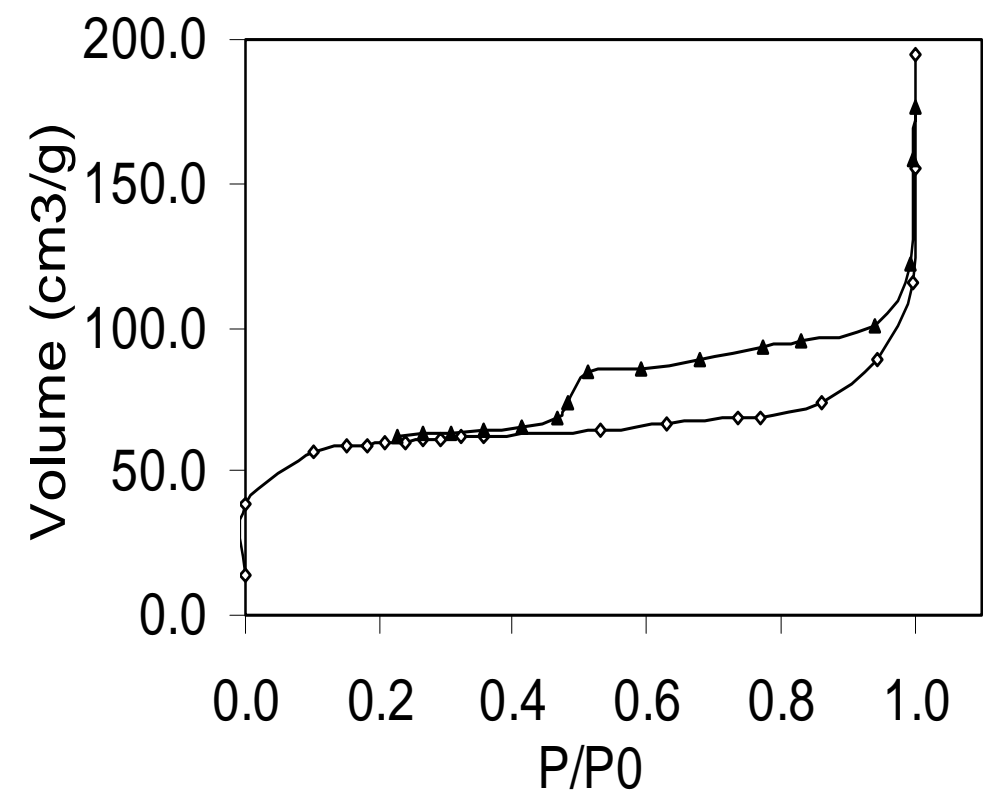

$\mathrm{S}$ Figure 5 showing the $\mathrm{N}_{2}$ adsorption/ desorption measurement of silica encapsulated $\mathrm{FePt}-\mathrm{Fe}_{3} \mathrm{O}_{4}$ indicating the Type I BET adsorption profile with surface area of $155.96 \mathrm{~m}^{2} \mathrm{~g}^{-1}$ with a sharp pore size distribution at $1.98 \mathrm{~nm}$. 